K.S. Chang PH D, R.T. Farrell в SC, J.W. Snellen MD PHD, F.G. King MD FRCP(C)

\title{
Calorimetrical com- parison of insulative properties of metalized plastic, clear polyethylene, and polyester blanket
}

The thermal insulation properties of metalized plastic sheeting (MPS), clear polyethylene sheeting (CPS) and 100 per cent polyester thermal bed blanket (TBB) were tested and compared quantitatively using direct calorimetry. The experiments were carried out on individual subjects sitting in a whole body calorimeter and covered first with a TBB bag up to the neck. Then the three materials were tested, one at a time, over the original $T B B$ up to the neck. The temperature of the calorimeter was set at normal operating room temperature of $18^{\circ} \mathrm{C}$. MPS provided the greatest reduction in sensible heat loss (SHL) of all three materials tested. The total SHL saving provided by an MPS over TBB was 29.7 per cent and was statistically highly significantly different from that provided by a CPS or TBB over TBB (the difference is 9.6 and 9.9 per cent, respectively, $p<0.001$ for both). While the $S H L$ saving provided by a CPS over TBB was 20.1 per cent, and $a T B B$ over $T B B$ was 19.8 percent, the difference of 0.3 per cent is statistically not significant $(p>0.5)$. An additional finding was that MPS is electrically conductive on one side. Precautions must be taken when it is used on patients connected to electrical devices. Also, insensible perspiration trapped inside the bag can be as much as $10 \mathrm{~g} \cdot$ hour $^{-1}$ and may become a problem when the patient is wrapped in MPS for an extended period of time.

\section{Key words}

MEASUREMENT TECHNIQUES: DIRECT CALORIMETRY EQUIPMENT: metalized plastic sheeting.

From the Calorimetry Laboratory, Basic Sciences Division and Discipline of Anaesthesia, Faculty of Medicine, Memorial University of Newfoundland.

Address correspondence to: Dr. K.S. Chang,

Calorimetry laboratory, Basic Sciences Division, Faculty of Medicine, Memorial University of Newfoundland, St. John's, Newfoundland A1B 3V6.
Excessive heat loss or hypothermia during surgery has been a problem associated with surgical procedures and of particular concern for the anesthetist. ${ }^{1-3}$ The resulting hypothermia is potentially dangerous to the patients during the recovery period when heat losses are restored through shivering and vasoconstriction. The increased metabolic demands can result in profound circulatory stress. ${ }^{4,5}$

In light of the recognised physiological disturbances associated with intra- and postoperative hypothermia, a variety of techniques have been proposed to reduce heat loss during surgery. These techniques include humidification of inspired gases, ${ }^{3,6}$ placing patients on a heated mattress, warming all intravenous fluids to body temperature ${ }^{5}$ and wrapping patients in insulation blankets.

The light-weight metalized plastic sheeting (MPS), was first applied in the manufacturing of pressure (space) suits used by astronauts of the Apollo program. ${ }^{7}$ Since then MPS has been widely adopted as one of the methods of preventing heat loss in patients during surgery or recovery after surgery. ${ }^{8-10}$ The reflective surface of the MPS acts to reduce radiative heat loss from the body while the very nature of the sheeting decreases convective heat losses by eliminating draughts. The relative insulative value of the MPS though is still somewhat controversal. Telfer-Brunton ${ }^{8}$ found MPS did not prevent a drop in oesophageal or rectal temperatures but showed a statistically significant reduction in heat loss obtained from thermometrically derived body heat content. Dyde and Lynn ${ }^{9}$ also found that MPS reduced the thermometrically calculated heat debt and almost abolished the fall in body temperature during thoracotomy. Radford and Thurlow ${ }^{10}$ found MPS to be ineffective in the prevention of a 
drop in mean oesophageal temperature during neurosurgery. Furthermore, several authors ${ }^{11-13}$ found that MPS does not offer significantly different thermal protection from clear polyethylene sheeting (CPS).

It appears then that the question of the relative value of MPS in reducing heat loss during surgery still remains unanswered. The purpose of this study was to provide an accurate assessment of the insulation value of MPS in comparison to clear polyethylene sheeting and to a thermal bed blanket, by using direct calorimetry rather than conventional methods of estimating body heat loss by thermometry.

\section{Methods}

The experiments were carried out using a whole body human calorimeter. The technical description and performance characteristics of the calorimeter have been published. ${ }^{14}$ In short, the calorimeter can measure the metabolic heat production, sensible and insensible heat exchange (water vapour loss times heat of vapourization) directly and continuously. In this study the main emphasis will be on sensible heat losses and water vapour losses.

Ten normal healthy subjects volunteered for the 12 experiments in this study. Their anthropometric data including the modified Du Bois body surface areas $^{15}$ are listed in Table I. The protocol of the experiment was approved by the Human Investigation Committee of the Faculty of Medicine. The subjects were informed of the total procedure involved. They were also informed that they were free to terminate their participation in the experiment without any explanation.

All experiments were carried out at a calorimeter temperature of $18.04 \pm 0.02 \mathrm{C}$, which is a normal operating room temperature, and a dew point temperature below $3^{\circ} \mathrm{C}$. The airflow through the calorimeter is about $12 \mathrm{~m}^{3} \cdot \mathrm{min}^{-1}$. Since the air is injected tangentially, there is considerable turbulence, especially when the subject is seated inside. The wind velocity to which the subject is exposed varies considerably from one area of his body surface to the other.

The materials tested in this study were: (a) Metalized plastic sheeting (MPS) or "Space Blanket" (Rescue sheet, Levitt-Safety Limited), which is a $10 \mu \mathrm{m}$ thick Mylar sheeting with thin aluminum coating. It was made into a bag $72 \mathrm{~cm} \times 212 \mathrm{~cm}$
TABLE I Anthropometric data of study subjects

\begin{tabular}{llll}
\hline Subject & $\begin{array}{l}\text { Body weight } \\
(\mathrm{kg})\end{array}$ & $\begin{array}{l}\text { Body height } \\
(\mathrm{cm})\end{array}$ & $\begin{array}{l}\text { Body surface area } \\
\left(\mathrm{m}^{2}\right)\end{array}$ \\
\hline 1 & 89.2 & 185.7 & 2.23 \\
2 & 78.0 & 175.0 & 2.04 \\
3 & 67.5 & 169.0 & 1.88 \\
4 & 80.0 & 181.0 & 2.10 \\
5 & 64.9 & 172.4 & 1.88 \\
6 & 69.0 & 174.0 & 1.94 \\
7 & 57.7 & 160.0 & 1.72 \\
8 & 63.0 & 163.3 & 1.80 \\
9 & 59.2 & 166.8 & 1.78 \\
10 & 70.5 & 183.4 & 2.02 \\
\hline
\end{tabular}

long, using clear plastic tape (Ruban HighlandTape, 3M Canada Inc.); (b) $16 \mu \mathrm{m}$ thick clear polyethylene sheeting (CPS) (Plastic Drop Cloth, Canadian Tire Corp.) was also made into a bag of the same size as the MPS using Ruban HighlandTape; (c) 100 per cent polyester thermal bed blanket (TBB) (G.A. Hardie Ltd., Toronto) which is an open knitted blanket sewn in the form of a bag $88 \mathrm{~cm} \times 229 \mathrm{~cm}$ long for the purpose of this study. In accordance with normal operating room and recovery room procedure, patients are covered by at least one layer of TBB before another covering of MPS or TBB is applied. The baseline for the tests carried out in this report were established with the subject covered with a TBB bag.

Each subject, clad only in shorts, entered the calorimeter and sat quietly for about 20 minutes until the calorimeter recovered from the opening of the door and the sensible heat loss showed a plateau varying not more than 1 watt for at least ten minutes. This part of the data will not be included in this report. Then he donned successively: (1) the TBB pulled up to the neck, (2) the MPS over the TBB up to the neck, (3) the CPS over the TBB up to the neck after removing the MPS and finally, (4) another TBB over the TBB up to the neck after removing the CPS. Each procedure was maintained until the SHL did not fluctuate more than 1 watt for at least ten minutes. The averages of these last ten minute readings were the total SHL. Except while donning the bags, the subjects were asked to maintain the same posture throughout the experiment.

Electrical resistance of the MPS between two points was estimated using a digital multimeter (Miconta, Radio Shack). 


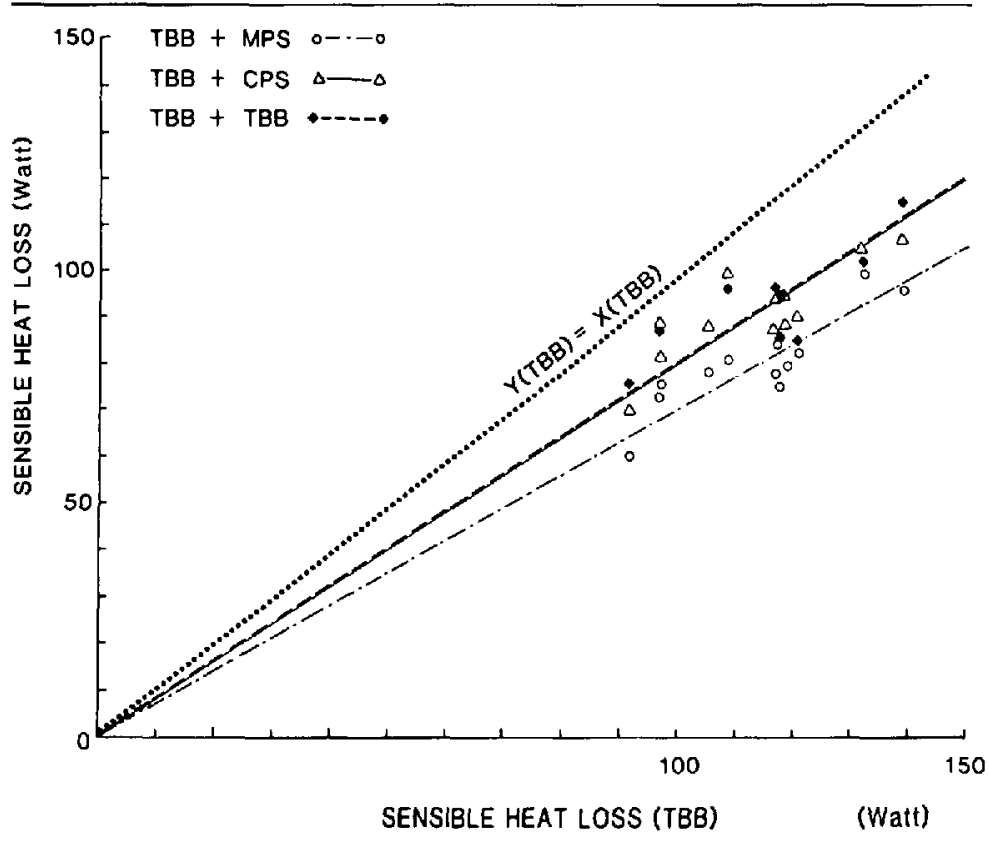

FIGURE The sensible heat loss measured directly when the subjects were covered with extra insulation material is plotted against those with only thermal bed blanket. The extra insulation layer being: clear polyethylene sheeting (CPS); thermal bed blanket (TBB); metalized plastic sheeting (MPS). The three regression lines are: —_CPS; .... TBB; -,-,. MPS. The dotted line represents the line of identity.

\section{Results}

The sensible heat losses (SHL) measured directly are displayed in the Figure, in which the total SHL obtained with one thermal bed blanket (TBB) is plotted on the abscissa and the other three sets of data (TBB + MPS, TBB + CPS, and TBB + TBB) are plotted on the ordinate. Each group of paired data indicates simple linear regression. The lines are constrained to run through the origin. It is reasonable to assume that when the SHL with one blanket is zero, the SHL with an extra layer of insulation will also be zero. The regressions are shown in Table II.

The $t$ test (two tailed) for the significance of the difference between two regression coefficients ${ }^{16}$ shows that the difference between the $\angle \mathrm{TBB}+$ MPS) and (TBB + CPS $\rangle$ is statistically highly significant (the difference is 9.6 per cent, $\mathrm{t}=3.99$, $\left.t_{0.001(2), v=17}=3.97\right)$. The same is the case between $\langle\mathrm{TBB}+\mathrm{MPS}\rangle$ and $\langle\mathrm{TBB}+\mathrm{TBB}\rangle$ (the difference is $\left.9.9 \%, \mathrm{t}=4.47, \mathrm{t}_{0.001(2), v=20}=3.85\right)$; but the difference between $\langle\mathrm{TBB}+\mathrm{CPS}\rangle$ and $\langle\mathrm{TBB}+$ TBB) is statistically not significant (the difference is 0.3 per cent, $t=0.12$ ). The line of identity in the Figure (dotted) represents the condition $Y(T B B)$ $=X(T B B)$. The difference $Y(T B B)-Y_{1}(T B B+$ MPS) represents the average amount of SHL saving in watts due to the addition of MPS over TBB, and is linearly dependent on the amount of SHL with TBB alone (Y(TBB) or X(TBB)). The difference of the slopes $\left(Y-Y_{1}\right) / X$, or $(1-0.703)$, or 29.7 per cent is the percentage saving of sensible heat loss due to the addition of a layer of MPS. For example, if the SHL with TBB alone is 100 watts, the saving due to addition of MPS over TBB would be 29.7 watts. Likewise, the percentage saving due to the addition of a layer of CPS, $\left(\mathrm{Y}-\mathrm{Y}_{2}\right) / \mathrm{X}$, or TBB over TBB, $\left(\mathrm{Y}-\mathrm{Y}_{3}\right) / \mathrm{X}$ is 20.1 and 19.8 per cent, respectively. The percentage saving of heat loss due to the addition of MPS over TBB instead of CPS or TBB over TBB is approximately ten per cent.

The observed average water vapour produc- 
TABLE II Regressions of the data in Figure

\begin{tabular}{|c|c|c|c|}
\hline $\mathrm{y}_{1}(\mathrm{TBB}+\mathrm{MPS})=0.703 \times(\mathrm{TBB})$ & $s_{y \cdot x}=5.19$ watt & $t=3.999 * * *$ & \\
\hline $\mathrm{y}_{2}(\mathrm{TBB}+\mathrm{CPS})=0.799 \times(\mathrm{TBB})$ & $s_{y, x}=5.85$ watt & & $t=4.47^{* * *}$ \\
\hline $\mathrm{y}_{3}(\mathrm{TBB}+\mathrm{TBB})=0.802 \times(\mathrm{TBB})$ & $s_{y . x}=7.33$ watt & $\begin{array}{c}\mathrm{t}=0.12 \\
\mathrm{~ns}\end{array}$ & \\
\hline
\end{tabular}

$\mathrm{X}(\mathrm{TBB}), \mathrm{Y}_{1}(\mathrm{TBB}+\mathrm{MPS}), \mathrm{Y}_{2}(\mathrm{TBB}+\mathrm{CPS}), \mathrm{Y}_{3}(\mathrm{TBB}+\mathrm{TBB})$ are the sensible heat loss (SHL) when the subject is covered with one layer of thermal bed blanket (TBB) up to the neck and an extra layer of metalized plastic sheeting (MPS), clear polyethylene sheeting (CPS), and TBB, respectively, $\mathrm{s}_{\mathrm{y} . \mathrm{x}}$ 's are the standard errors of estimate and $t$ 's are the $t$ tests between two simple linear regressions.

$* * *=$ highly significant.

tion of all subjects from the whole body is 0.15 $\mathrm{g} \cdot \mathrm{min}^{-1} \cdot \mathrm{m}^{-2}$ at the selected calorimeter conditions, but in the CPS or MPS is is only $0.08 \mathrm{~g} \cdot \mathrm{min}^{-1}$. $\mathrm{m}^{-2}$, which represents the water vapour production from the head and respiratory tract, because the CPS and MPS act as vapour barriers. The difference between the two values represents the insensible perspiration produced by the rest of the body surface. This produced water vapour was also seen condensing on the inner surface of CPS.

The electrical resistance measured at two points on the aluminum coated side of the MPS $0.5 \mathrm{~m}$ apart was of the order of $0.5 \mathrm{~K} \Omega$. The resistance measured at two points on the Mylar side, or one on each side was infinity. The electrical continuity of the aluminium coating is easily broken when the MPS is wrinkled.

\section{Discussion}

We have made a quantitative comparison of the amount of sensible heat loss (SHL) saving between three different materials: thermal bed blanket (TBB), metalized plastic sheeting (MPS), and clear polyethylene sheeting (CPS). In all these cases the subjects donned themselves one at a time, with the above materials, in the form of a bag, covered up to the neck. The SHL from the head remains unchanged. Therefore the saving in SHL by the above three different materials will definitely be more if the head were also covered. On the other hand, a patient in a hospital normally lies on a thick, well insulated mattress and is covered with blanket material up to the neck. The surface area in contact with the mattress is not available for convective and radiative heat exchanges. The SHL from the head and the part of the body in contact with the mattress remain unchanged. Therefore, the savings in SHL by the above materials will be less than what were measured here.

Human skin continuously produces water on the skin surface, it is produced through the diffusion of water and sweat gland activity. Even in an extremely cold environment, sweat production is the major component of insensible perspiration from the skin. ${ }^{17}$ For a subject with a skin surface area of about $2 \mathrm{~m}^{2}$, this water production from the skin can be as much as $10 \mathrm{~g} \cdot$ hour $^{-1}$. Should the patient be covered for an extended period of time, this should be taken into consideration.

The exceptional portability of MPS is not a big advantage for a hospital, where TBB is readily available, and when requested, preheated TBB can also be provided easily by the hospital staff. Two additional TBB's will provide a saving in total SHL of approximately $20 \%+(1-20 \%) \times 20 \%=$ $36 \%$, which is more than the saving from one additional MPS. In a hospital, there is no difficulty in procuring the extra TBB's. Finally, MPS has thin aluminium coating on one side of the Mylar sheeting, which makes it electrically conductive on this side. When in use on patients with electrical devices attached, special precaution must be made to prevent any electrical hazard.

If the sensible heat loss alone is considered, MPS provides the best insulation of all the three materials tested. The total SHL saving by MPS is 29.7 per cent and is statistically highly significantly different from the other two. While the SHL saving provided by CPS and TBB is 20.1 and 19.8 per cent respectively, the difference is not significant.

\section{Acknowledgements}

We appreciate the financial support of the Offshore Operators Division of the Canadian Petroleum 
Association. We thank the volunteers for their participation, the Department of Community Medicine for the loan of the word processor, and Mrs. Therese Thorne for retyping the manuscript that was accidently lost from the computer file.

\section{References}

1 Holdcroft $A$, Hall GM. Heat loss during anaesthesia. Br J Anaesth 1978; 50: 157-64.

2 Hall GM. Body temperature and anaesthesia. $\mathrm{Br}$ J Anaesth 1978; 50: 39-44.

3 Shanks $C A$. Humidification and loss of body heat during anaesthesia. II: effects in surgical patients Br J Anaesth 1974; 46: 863-6.

4 Bay J, Nunn JF, Prys-Roberts C. Factors influencing arterial $\mathrm{PO}_{2}$ during recovery from anaesthesia. Br J Anaesth 1968; 40: 398-407.

5 Newton DEF. The effect of anaesthetic gas humidification on body temperature. $\mathrm{Br} J$ Anaesth 1975; 47: 1026.

6 Newman BJ. Control of acidental hypothermia. Occurrence and prevention of accidental hypothermia during vascular surgery. Anaesthesia 1971;26: 177-87.

7 Huber CS, Heidelbaugh ND, Rapp RM, Smith $M C J r$. Nutrition systems for pressure suits. Aerospace Med 1973; 44: 905-9.

8 Telfer-Brunton JLA, Thoms GMM, Blair I. Reduction of heat loss in neurosurgucal patients using metallized plastic sheeting. Br J Anaesth 1982; 54: 1201-5.

9 Dyde JA, Lunn HF. Heat loss during thoractomy. A preliminary repor. Thorax 1970; 25: 355-58.

10 Radford $P$, Thurlow AC. Metalliscd plastic shecting in the prevention of hypothermia during neurosurgery. Br J Anaesth 1979; 51: 237-40.

11 Marcus $P$, Robertson D, Langford $R$. Metallised plastic sheeting for use in survival. Aviat Space Environ Med 1977; 48: 50-2.

12 Light IM, Norman $J N$. The thermal properties of a survival bag incorporating metallised plastic sheeting. Aviat Space Environ Med 1980; 51: 367-70.

13 Light IM, Dingwall RHM, Norman JN. The thermal protection offered by lightweight survival systems. Aviat Space Environ Med 1980; 51: 1100-3.

14 Snellen JW, Chang KS, Smith S. Technical description and performance characteristics of a human whole-body calorimeter. Med Biol Eng Comput 1983; 21 : 9-20.
15 Mitchell D. Strydom NB, Van Graan CH, Van der Walt WH. Human surface area: comparison of the Du Bois formula with direct photometric measurement. Pflügers Arch 1971; 325: 188-90.

16 Zar JH. Biostatistical analysis. 2nd ed. Englewood Cliffs: Prentice-Hall, Inc., 1984.

17 Rothman S. Physiology and biochemistry of the skin. Chicago: University of Chicago Press, 1954.

\section{Résumé}

On a évalué et comparé les propriétés isolantes d'une feuille de plastique métallisé (MPS), d' une membrane de polyéthylène transparent (CPS) et d'une couverture entièrement tissée de polyester (TBB). On a effectué des mesures directes de calorimétrie sur des sujets assis dans un calorimètre corporel. On a d'abord effectué les mesures alors que les sujets étaient recouverts de la couverture de polyester (TBB). Enswite les mesures de perte de chaleur ont été faites après avoir posé, pardessus la couverture de polyester, chacun des matériaux à tour de rôle. La température du calorimètre a êté réglée à $18^{\circ} \mathrm{C}$, soit une température normale de salle d'opération. Le plastique métallisé s'est montré le plus efficace pour réduire la perte de chaleur perceptible. Ce matériau recouvrant une couverture de polyester permet de réduire la perte de chaleur de 29.7 pour cent, ce qui est une différence statistiquement très significative comparée à la membrane de polyéthylène ou la seconde couverture de polyester (la différence est de 9.6 et 9.9 pour cent respectivement, $p<0.001$.) Les réductions de perie de chaleur obtenues par la membrane de polyéthylène et la couverture de polyester n'étaient pas significativentent différentes ( $p>0.5$ ). Au cours de cette expérience, on a aussi observé que la feuille de plastique métallisé est électriquement conductive sur une de ses faces; ceci commande certaines précautions chez les patients raccordés à des appareils électriques. De même la transpiration sous ce type de couverture peut aller jusqu'à $10 \mathrm{~g}$ par heure et peut constiuer un problème chez le patient enveloppé dans une membrane de plastique métallisé pendant des périodes prolongées. 